\title{
NUCLEAR DNA CONTENT OF THREE CREPIS SPECIES
}

\author{
H. WALLACE, C. A. SPARKES and M. MADEN \\ Department of Genetics, University of Birmingham, Birmingham B15 2TT, \\ England
}

Received 24.vii.72

\section{INTRODUCTION}

VARIOUs comparisons made on series of animals and plants have established correlations between the size of the genome, measured as the diploid nuclear (2C) DNA content, the combined volume of metaphase chromosomes, the interphase nuclear volume, and cell size. DNA content is also correlated to the duration of the mitotic cycle and of its period of DNA replication (S phase) in Angiosperm root-tips (Van't Hof, 1965; Evans and Rees, 1971). It is rarely pointed out that the variability of these features and the imprecision of their measurement may well permit only the vague conclusion that the correlations are all positive. Vicia faba provides an outrageous example of imprecision, with a 2C DNA content calculated to be either 24 or $40 \mathrm{pg}$. and various measurements of the mitotic cycle ranging from 14 to 19 hours. Under the stipulated conditions of colchicine arrest and feulgen staining, chromosome volume is closely correlated to DNA content within different Angiosperm genera (Jones and Rees, 1968; Rees and Hazarika, 1969) but the regression lines differ considerably between genera (Evans and Rees, 1971). Other examples and exceptions are cited by Lints and Jones (1969) and by Bennett and Rees (1969).

It is on the basis of such a correlation that Crepis neglecta and $C$. fuliginosa have been held to provide an exceptionally striking case of genomic difference between closely related species of Angiosperms. Tobgy (1943) measured the chromosomes at mitotic metaphase in these two species and their hybrid, finding that the haploid set of fuliginosa chromosomes was 55.5 per cent. the length, 67 per cent. the diameter and thus only 25 per cent. the volume of the neglecta set. Despite these differences, the two species naturally interbreed to produce viable but very infertile hybrids. Tobgy demonstrated that the three fuliginosa chromosomes could have arisen by means of reciprocal translocations and the loss of only one arm and centromere from the four neglecta chromosomes-a loss of less than 10 per cent. of the total metaphase length or volume. The fuliginosa chromosomes pair and form chiasmata with virtually all the neglecta chromosomes during meiosis in the hybrid. Tobgy (1943) concluded from these observations that the chromosome differences at metaphase were largely differences of contraction, not of material. Both Stebbins (1966) and Callan (1967), however, chose the volume difference to illustrate their theories concerning the evolution and organisation of chromosomes.

We have measured the DNA content of nuclei in primary root-tips of these two species and of $C$. capillaris, believing that even our inexperience and a temperamental microdensitometer could not prevent us from distinguishing between the predictions that $C$. fuliginosa nuclei contain either 25 per cent. or 90 per cent. as much DNA as C. neglecta nuclei. 


\section{MAterial AND METHODS}

Seeds were germinated on filter paper until both the primary root and the cotyledons had emerged, and then processed according to the optimum conditions established for Vicia faba by Fox (1969): fixation in ethanolacetic $(3: 1)$ for at least 24 hours, hydrolysis in $5 \mathrm{~N} \mathrm{HCl}$ for 1 hour, staining in Feulgen $p \mathrm{H} 3.6$ for 2 hours followed by three 10 -minute washes in $0.03 \mathrm{M}$ $\mathrm{SO}_{2}$ and mounting in glycerol, all at room temperature. The absorption of green light (nominally $560 \mathrm{~nm}$.) by nuclei in cubical cells of the apical $\mathrm{mm}$ of the root was recorded as the mean of three readings, less blank background readings, on a Barr and Stroud GN2 integrating microdensitometer.

C. capillaris roots were originally intended to serve as a standard for converting all measurements into absolute units. The $2 \mathrm{C}$ DNA content of C. capillaris has been estimated as $2.45 \mathrm{pg}$. and as $4.2 \mathrm{pg}$. Our reasons for distrusting both estimates are given in the discussion. As an alternative standard, blood smears from the toad Xenopus laevis were dried on slides and then processed identically to the seedlings. All Xenopus erythrocytes are expected to contain the $2 \mathrm{C}$ value of $6.3 \mathrm{pg}$. DNA (Dawid, 1965). We have tested their suitability as standards for Feulgen densitometry. One obvious source of error is that erythrocyte nuclei are relatively small but densely stained. All nuclei were crushed to reduce the known tendency of microdensitometers to underestimate the staining of condensed chromatin and chromocentres.

\section{Results}

Initial densitometer readings of potentially meristematic cells produced a distribution of absorption classes, mostly within a two-fold range for each plant species and thus presumably including $2 \mathrm{G}, 4 \mathrm{G}$ and intermediate (S-phase) nuclei. Although $2 \mathrm{C}$ nuclei predominated in these distributions (fig. 1), the expected $2 \mathrm{C}$ and $4 \mathrm{C}$ modes could not be clearly identified. The frequency distributions do not correspond well to expectations derived from the durations of $G_{1}, S$ and $G_{2}$ phases of the mitotic cycle (Langridge, O'Malley and Wallace, 1971), but do resemble the distributions reported by McLeish and Sunderland (1961) from both meristematic and differentiating zones in root-tips of several Angiosperms. In these cases there appear to be populations of non-dividing or rarely dividing $4 \mathrm{C}$ cells. We tested this possibility by immersing neglecta seedlings in $10^{-6} \mathrm{M}$ FUdR (5-fluorodeoxyuridine) for 6 hours prior to fixing and processing. This treatment should inhibit DNA synthesis and arrest cells in S-phase long enough for $\mathrm{G}_{2}$ cells to pass through mitosis into $G_{1}$ (Taylor, Haut and Tung, 1962). In terms of densitometry, that should deplete the $4 \mathrm{C}$ category and augment the $2 \mathrm{G}$ category to the extent that the sample consists of meristematic cells. The FUdR treatment was effective in abolishing mitotic figures but did not significantly alter the frequency distribution of absorption classes from that of control seedlings or from that shown in fig. 1 . We conclude that there is a population of persistent $4 \mathrm{C}$ cells even in the apical $1 \mathrm{~mm}$ of these small roots.

Selected nuclei from the root-tips, identified as being at late telophase to early interphase or late interphase to early prophase, were then recorded from each species and compared to erythrocyte nuclei. Fig. 2 shows one 


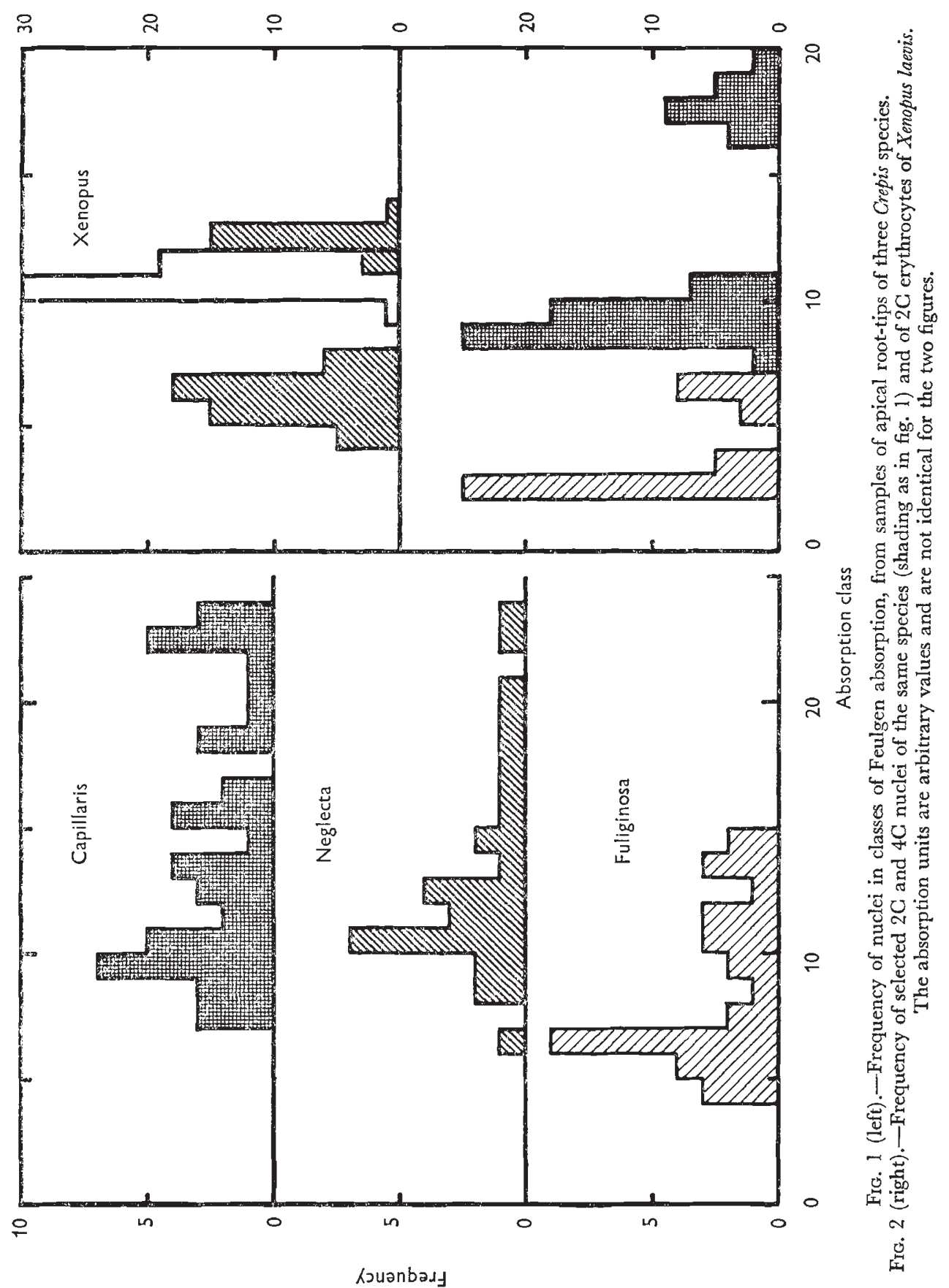


series of readings, accumulated by two recordings for each species on consecutive days and thus perhaps exaggerating their variability. A second series of readings was made under the same conditions from similar numbers of nuclei. After adjustment for the $2 \mathrm{C}$ and $4 \mathrm{C}$ categories of nuclei, the mean values of these results provide our best estimate of the relative and absolute amounts of DNA (table 1).

The comparisons made in table 1 assume that Feulgen staining has the same stoichiometric relationship to nuclear DNA in blood smears and whole root-tips. In fact, Feulgen densitometry has only been justified in terms of yielding appropriate recordings in polyploid series for chromatin of a particular species, consistent results between either plant species or animal species, and with identical preparations such as isolated nuclei. In our comparison, blood smears might well reach saturation and lose excess stain more rapidly than the root-tips, whose bulk and cell walls should impede the diffusion of stain equally in both directions. Varying the time of staining shows that both roots and blood smears reach saturation within the 2 hours used in the standard procedure (fig. 3 ). The saturation curves are so similar that relative staining seems proportional relative DNA content at all times: there is no evidence of a diffusion effect. Only unbound reagent is lost

TABLE 1

Relative and absolute DNA contents of $2 C$ nuclei. (Mean values from n nuclei in 2 series of recordings)

\begin{tabular}{|c|c|c|c|c|}
\hline Species & $n$ & \multicolumn{2}{|c|}{ Relative absorption } & pg. DNA \\
\hline C. capillaris & $\begin{array}{l}72 \\
50\end{array}$ & $\begin{array}{l}9 \cdot 38 \\
9 \cdot 12\end{array}$ & $\begin{array}{l}100 \% \\
100 \%\end{array}$ & $\left.\begin{array}{l}5 \cdot 3 \\
5 \cdot 1\end{array}\right\} 5 \cdot 2$ \\
\hline C. neglecta & $\begin{array}{l}63 \\
38\end{array}$ & $\begin{array}{l}6 \cdot 51 \\
6 \cdot 30\end{array}$ & $\begin{array}{l}69 \% \\
69 \%\end{array}$ & $\left.\begin{array}{l}3.7 \\
3.5\end{array}\right\}$ \\
\hline C. fuliginosa & $\begin{array}{l}41 \\
59\end{array}$ & $\begin{array}{l}3 \cdot 25 \\
3 \cdot 06\end{array}$ & $\begin{array}{l}35 \% \\
34 \%\end{array}$ & $\left.\begin{array}{l}1.8 \\
1.7\end{array}\right\} 1 \cdot 8$ \\
\hline X. laevis & $\begin{array}{l}50 \\
80\end{array}$ & $\begin{array}{l}11 \cdot 22 \\
11 \cdot 35\end{array}$ & $\begin{array}{l}120 \% \\
124 \%\end{array}$ & $\left.\begin{array}{l}6 \cdot 3 \\
6 \cdot 3\end{array}\right\}$ standard \\
\hline
\end{tabular}

during the $\mathrm{SO}_{2}$ washes, while any that remains quickly reaches equilibrium throughout the glycerol mounting medium. As a consequence, the recorded difference between a nucleus and an equal area of blank background measures only bound stain, and is identical after 1 minute and the standard 30-minute $\mathrm{SO}_{2}$ treatment (fig. 4). Blood smears do not lose stain for several hours in distilled water but can give perceptibly lower recordings after storage overnight in water. In our standard procedure, blood smears were mounted in glycerol within a few minutes after washing. We have tested several other variations of the staining procedure and found the same responses and optimal conditions described by Fox (1969) for Vicia faba root-tips. Blood smears and seedlings can be stored at $4^{\circ} \mathrm{C}$. for several weeks in the fixative, or for at least a week when mounted in glycerol, and still yield consistent densitometer readings. Blood smears and root-tips stain maximally after 60 minutes' hydrolysis at $20^{\circ}-22^{\circ}$ G. Since the material responded identically to these variations in the staining procedure, and all preparations were crushed sufficiently to give constant densitometer readings, we conclude that nuclear DNA contents of plant roots and animal erythrocytes can be validly compared. 


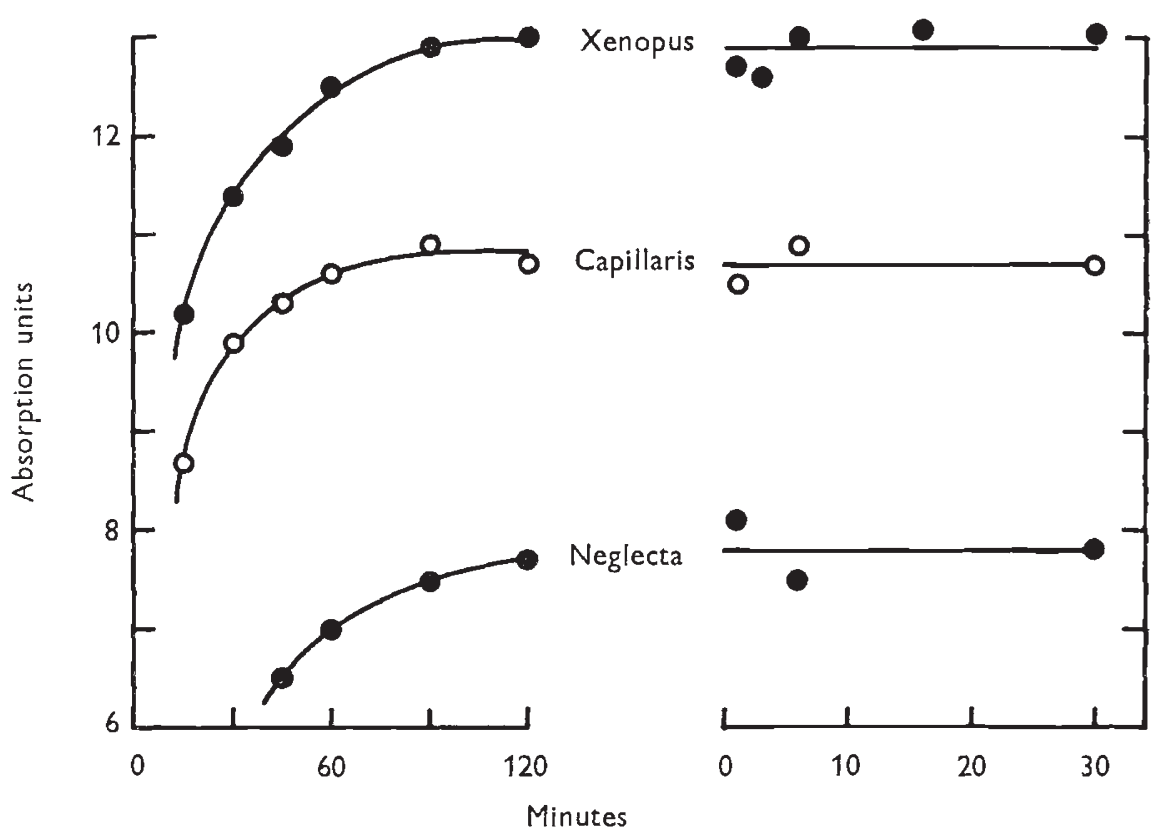

Fig. 3 (left).-Saturation curves for Feulgen staining. The mean absorption of ten 2C nuclei is plotted against time of staining, in each case followed by 30 minutes in $\mathrm{SO}_{2}$.

FIG. 4 (right).-The mean absorption of ten $2 \mathrm{C}$ nuclei is not affected by altering the time of $\mathrm{SO}_{2}$ treatment, in preparations stained for 2 hours.

\section{Discussion}

Previous estimates of the DNA content of plant cells are derived from chemical determinations and cell counts of root-tips, which are sometimes naïvely considered to represent a 3C value. Van't Hof (1965) derived a more sophisticated estimate of $2 \mathrm{C}$ by assuming the frequencies of $2 \mathrm{C}$, intermediate, and $4 \mathrm{C}$ cells were proportionate to the relative durations of the similar compartments of the mitotic cycle: $G_{1}, S$ and $G_{2}+M$, which should be true for the meristem. Thus he corrected his determination for C. capillaris from $3.82 \mathrm{pg}$./cell to a $2 \mathrm{C}$ value of $2.45 \mathrm{pg}$. He also adjusted a previous determination of $54.3 \mathrm{pg}$./cell for Allium cepa to a $2 \mathrm{C}$ value of $33.55 \mathrm{pg}$. The latter estimate has been used as a standard for Feulgen densitometry by Evans and Rees (1971), who thus indirectly estimated the 2C DNA content of C. capillaris as $4 \cdot 2$ pg. McLeish and Sunderland (1961) had previously obtained a quite different result, $78.7 \mathrm{pg} . / \mathrm{cell}$, for the DNA of $A$. cepa roots. Only a fault in extraction or measurement can explain the discrepancy between 78.7 and $54.3 \mathrm{pg}$./cell. The histograms of densitometer readings shown by McLeish and Sunderland (1961) and confirmed here invalidate the assumption required for Van't Hof's (1965) correction factor. This would only alter the estimated $2 \mathrm{C}$ value for $A$. cepa by about a picogram, but could well be larger for other species.

It seems that the errors and uncertainties reviewed in the last paragraph have prevented attempts to obtain reliable estimates of the $2 \mathrm{C}$ DNA content of Angiosperms. In contrast to this, we can vouch for the reliability of 
Dawid's (1965) conclusion, from diphenylamine determinations and cell counts, that Xenopus laevis erythrocytes contain $6 \cdot 3 \pm 0 \cdot 6$ pg. DNA. By the less accurate method of absorption at $265 \mathrm{~nm}$., blood from three adult females yielded $6 \cdot 0,6 \cdot 3$ and $6 \cdot 5 \mathrm{pg}$. (Wallace, unpublished). Circulating erythrocytes are apparently incapable of DNA synthesis, and yield relatively uniform densitometer readings (fig. 2). Considering the specificity of the Feulgen. reaction and the similar effects on erythrocytes and root-tips of varying the staining procedure, we can fairly claim that we have obtained good relative measurements of nuclear DNA, conforming to assumptions which are generally accepted for Feulgen densitometry. Furthermore, erythrocytes provide a much more reliable standard than has been used previously for estimating the DNA content of Angiosperm nuclei. This conclusion suggests a general technique of standardising densitometer readings, for virtually any eukaryotic cell could be compared to erythrocytes of an appropriate fish, amphibian, reptile or bird-covering the range of $1-168 \mathrm{pg}$./nucleus (see Mirsky and Osawa, 1961). Bachmann (1972) has anticipated this suggestion by standardising his measurements of DNA for several mammals against amphibian erythrocytes.

The possibility of error is greatly reduced when considering only the relative densitometer recordings from root-tips of related plants. We find that $C$. fuliginosa nuclei contain 50 per cent. as much DNA as the corresponding nuclei of $C$. neglecta. The rather greater amount of heterochromatin in neglecta nuclei could only introduce a trivial bias into this result, which does not confirm to either prediction (25 or 90 per cent.) mentioned in the introduction. We should conclude from our results that such predictions were completely unreliable, except that Jones and Rees (1968) find a good consistency between DNA content and both total metaphase chromosome volume and pachytene pairing on an Allium hybrid. Although the relative DNA content of fuliginos a and neglecta corresponds reasonably well with their relative chromosome lengths at mitotic metaphase, 55.5 per cent. (Tobgy, 1943), we suppose that must be a coincidence. Metaphase length seems to be a much poorer measure of DNA content than metaphase volume (Jones and Rees, 1968) and is obviously affected by the speed of division or type of cellular differentiation, as shown by the extreme contraction of chromosomes after prolonged colchicine treatment and the unusual lengths of chromosomes in embryonic divisions (cf. Navashin, 1934). It seems that several of the correlations cited in the introduction may be too vague to be useful for any general predictive purpose. Any insight into cell metabolism gained from such correlations is also suspect on account of the errors involved.

\section{Summary}

1. The relative DNA content of diploid nuclei has been estimated by feulgen densitometry for Crepis capillaris, C. neglecta and C. fuliginosa.

2. These relative measurements have been converted to absolute units by use of Xenopvs laevis erythrocytes as a standard.

3. It is claimed that this technique is an improvement on previously unreliable estimates of the nuclear DNA content of Angiosperms.

Acknowledgment.-Some of these results were extracted from the report on an honours project. We are obliged to Ian Lenox-Smith of Roche Products Ltd. for a sample of FUdR. 


\section{REFERENGES}

Bachmann, к. 1972. Genome size in mammals. Chromosoma, 37, 85-93.

BENNETT, M. D., AND REES, H. 1969. Induced and developmental variation in chromosomes of meristematic cells. Chromosoma, 27, 226-244.

CAllan, H. G. 1967. The organization of genetic units in chromosomes. 7. Cell Sci., 2, $1-7$.

DAWID, I. B. 1965. Deoxyribonucleic acid in amphibian eggs. 7. molec. Biol., 12, 581-599. EVANS, G. M., AND REEs, H. 1971. Mitotic cycles in Dicotyledons and Monocotyledons. Nature, 233, 350-351.

FOX, D. P. 1969. Some characteristics of the cold hydrolysis technique for staining plant tissues by the feulgen reaction. J. Histochem. Cytochem., 17, 266-272.

JONES, R. N., AND REES, H. 1968. Nuclear DNA variation in Allium. Heredity, 23, 591-605. LANGRIDGE, W. H. R., O'MALleY, T. A., AND WALlACE, H. 1970. Neutral amphiplasty and regulation of the cell cycle. Proc. Nat. Acad. Sci., U.S., 67, 1894-1900.

LINTS, F. A., AND JONES, R. N. 1969. Effect of heterochromatin on the relationship between nuclear DNA content and chromosome volume. Heredity, 24, 14.7-151.

MCLEISH, J., AND SUNDERLAND, N. 1961. Measurements of desoxyribosenucleic acid (DNA) in higher plants by feulgen photometry and chemical methods. Exp. Cell Res., 24, 527-540.

MIRSKY, A. E., AND OSAWA, s. 1961. The Interphase Nucleus. In: The Cell (edit. J. Brachet and A. E. Mirsky), vol. II, pp. 677-763. Academic Press, N.Y.

NAvASHIN, M. 1934. Chromosome alterations caused by hybridization and their bearing upon certain general genetic problems. Cytologia, 5, 169-203.

REES, H., AND HAzARIKA, M. H. 1969. Chromosome evolution in Lathyrus. In: Chromosomes Today Vol II (edit. C. D. Darlington and K. R. Lewis), pp. 158-165. Oliver \& Boyd, Edinburgh.

stebbins, G. L. 1966. Chromosomal variation and evolution. Science, 152, 1463-1469.

TAYLOR, J. H., HAUT, W. F., AND TUNG, J. 1962. Effects of fluorodeoxyuridine on DNA replication, chromosome breakage, and reunion. Proc. Nat. Acad. Sci. U.S., 48, 190-198.

TOBGY, H. A. 1943. A cytological study of Crepis fuliginosa, C. neglecta, and their $\mathrm{F}_{1}$ hybrid, and its bearing on the mechanism of phylogenetic reduction in chromosome number. 7. Genet., 45, 67-111.

VAN'T HOF, J. 1965. Relationships between mitotic cycle duration, $\mathrm{S}$ period duration and the average rate of DNA synthesis in the root meristem cells of several plants. Exp. Cell Res., 39, 48-58. 